\title{
Strains of Rodents and the Pharmacology of Learning and Memory
}

\author{
Martine Ammassari-Teule ${ }^{1,2}$ and Claudio Castellano ${ }^{1}$ \\ ${ }^{1}$ CNR Institute of Neuroscience, Laboratory of Psychobiology and Psychopharmacology, \\ Rome, Italy; ${ }^{2}$ IRCCS S. Lucia Foundation, Rome, Italy
}

\begin{abstract}
SUMMARY
Mendelian genetic tools have extensively been used to improve the description of the pharmacological mechanisms involved in learning and memory. The first part of this short review describes experiments involving the bidirectional selection of rats or mice for extreme behavioral characteristics or for sensitivity to pharmacological treatments. The second part focuses specifically on inbreeding. In conclusion, the advantages and the limits of a Mendelian pharmacogenetic approach of learning and memory are discussed.
\end{abstract}

\section{INTRODUCTION}

The idea that genes can affect behavior and that variability in behavior among species, populations, or individuals has some genetic basis is now widely accepted. Evolutionary biologists have been primarily interested in this issue to assess whether variation in behavior within a species had any genetic basis and, if so, how genetic variation was maintained across generations. The interest of neuroscientists for behavior genetics developed later, that is, when it

Reprint requests to: M. Ammassari-Teule CNR Institute of Neuroscience, Laboratory of Psychobiology and Psychopharmacology, IRCCS S. Lucia Foundation, 306 Via Ardeatina, 00179-Rome Italy. E-mail address: 1.restivo@hsantalucia.it became apparent that genetically associated variations in behavior were providing a powerful tool for revealing correlated variations in brain architecture, neurochemistry, and neural plasticity. This approach was fundamentally based upon the principle that phenotypic characters in a population cannot be classified into discrete categories but are distributed quantitatively over a Gaussian (bellshape) curve. This phenomenon means that in a natural population-even if such characters are continually varying - most individuals are grouped around the central value of the Gaussian curve and tend to present similar phenotypes. Artificial selection techniques, however, allow the generation of well-differentiated subpopulations showing robust-sometimes extreme-differences in behavioral traits with rather 'intra-population' homogeneity. This subdivision, in turn, makes it possible to describe the neural characteristics of each subgroup and, therefore, to identify accurately the neural substrate of specific behaviors. In rodents, bidirectional selection and inbreeding represent the most widely used tools. The aim of the present paper is to underline the importance of such tools in the analysis of the pharmacological aspects of learning and memory. The first part focuses on bidirectional selection-that is, on rat or mouse lines selected for opposite behavioral characteristics or for sensitivity to pharmacological treatments. The second part concerns experiments specifically carried out in inbred strains of mice showing distinct genetically associated learning and memory abilities, although no behavioral criterion is involved in the selection 
process. In conclusion, the advantages and the limits of a genetic dissection based upon Mendelian principles in the field of pharmacology of memory are discussed.

\section{BIDIRECTIONAL SELECTION}

\section{Behavioral traits}

Bidirectional selection for behavioral traits consists of submitting large samples of rodents to a given situation and scoring their behavior. Males and females reaching the higher scores are systematically mated, as are males and females reaching the lower scores. Following several generations, this selection, strictly based upon a performance criterion, provides two welldifferentiated subpopulations, allowing a search for the neural markers of each behavioral profile. For example, rats selected by Tryon (1940), Heron (1941), or Thompson (1954) for their poor versus good maze-learning abilities, or by Bignami (1965), as well as by Brush (1979), for their high versus low active avoidance scores were the result of a bidirectional selection strictly based upon a learning performance criterion. Nevertheless, as every learning task involves sensorial, emotional, and motivational peculiarities, it became rapidly clear that a number of other behavioral traits were also segregated in high and low learners. For example, Brush (1979), who selected the Syracuse (SHA/bru and SLA/bru) lines of hooded rats for differences in active two-way shuttle box avoidance learning, recently claimed (2003a, b) that the lowavoidance phenotype (SLA) was better characterized in terms of a high level of anxiety, whereas the reverse was true for the high avoidance phenotype (SHA). The author concluded that having selected rats for a difference in avoidance learning, factors in the affective domain influencing more performance than learning per se were the primary selected traits.
This aspect illustrates, in fact, the most criticized aspect of this selection method, namely, that possible confounders cannot be excluded when conclusions regarding the neural bases of learning and memory are drawn from experiments involving bidirectional selection based upon a performance criterion. An indirect demonstration of this aspect was provided by rats not bred for differences in learning performance, like the Maudsley reactive and non-reactive lines, selected for their different level of emotionality (defecation) in an open field (Broadhurst, 1960), or the Naples High-Excitable and Naples Low-Excitable rat lines, selectively bred since 1976 by Sadile and colleagues (see Lipp et al., 1987) on the basis of different behavior arousal in a novel situation. All these lines show line-dependent specific learning abilities. Nevertheless, these strains have been successfully used to emphasize an aspect of particular relevance for pharmacological studies, i.e., that responsiveness to one drug strongly varies as a function of the genetic background.

This phenomenon, early suggested by Broadhurst (1964) was reported for the first time in Roman high-avoider (RHA) and Roman lowavoider (RLA) rats selected by Bignami (1965) for extreme active avoidance scores. Injecting such rats with amphetamine and other psychotropic agents, before the training sessions, Bignami and colleagues found a selective enhancing effect of drugs on RLA performance.

Indeed this observation was followed by a number of experiments showing that many drugs exert line-specific effects on memorization. Among those, two findings require particular attention. First, differences in the opiate binding and behavioral effects of morphine were found between RLA and RHA injected with morphine (Lazega et al., 1986), already suggesting (1) a genetic-dependent responsiveness to opiates and (2) the possibility of searching for mechanisms common to memory and drug addiction. Second, the observation that rats differing in active avoidance 
scores also showed distinct performance-related traits allowed a more precise identification of drug targets. For example, Satinder (1980) observed that scopolamine disrupted responsiveness to visual but not to auditory stimuli in the RLA line, whereas d-amphetamine, otherwise affecting activity and reaction time, did not affect this parameter. Satinder suggested that responsiveness to visual stimuli is influenced by bidirectional genetic selection via the segregation of linespecific cholinergic mechanisms.

The observation that heritable factors control the responsiveness to drugs clearly led to analyses of the consequence of bidirectional selection at the neurochemical level. Using the same rats, Giorgi et al. (1994) reported line-specific differences relating to the GABAergic and dopaminergic systems. In particular, the authors showed that the stimulatory effect of GABA on ${ }^{36} \mathrm{Cl}$ uptake was less pronounced in the cerebral cortex of RLA as compared with RHA, whereas no line-related change was detected in $\left[{ }^{3} \mathrm{H}\right] \mathrm{GABA}$ and $\left[{ }^{3} \mathrm{H}\right]$ flunitrazepam binding. For dopamine, the density of D1 dopamine receptors was found to be lower in the nucleus accumbens of RLA as compared with RHA, whereas no linedependent change was observed for D1 dopamine receptors located in the striatum, the amygdala, and the prefrontal cortex. Thus, site-specific biochemical markers of inter-individual variability in emotional learning were identified.

The possibility of observing neurochemical differences in lines of rats selected for behavioral traits has rapidly been considered a valuable tool for describing the role of various neurotransmitters in cognition. For example, investigations on the neurochemical characteristics of inbred Maudsley Reactive (MR) and Non-Reactive (MNR) rat strains showed that MR rats had lower concentrations of norepinephrine in the hypo-thalamus than MNRA rats. By contrast, MR rats had a higher concentration of telencephalic norepinephrine than MNRA rats (Liang \& Blizard, 1978). Possibly indicative of a higher rate of norepinephrine metabolism, the percentage of ${ }^{3} \mathrm{H}$-labeled noncatechol metabolites relative to the total counts was higher in the brainstem of MNRA rats when measured 90 minutes after the intraventricular injection of ${ }^{3} \mathrm{H}$-norepinephrine (Slater et al., 1977). Interestingly, both lines showed an elevation of 3,4 dihydroxiphenylacetic acid levels in the locus coeruleus following a single session of acute immobilization stress compared with non stressed controls, but this elevation was stronger in the reactive line (Buda et al., 1994). Such wellcharacterized differences between noradrenergic and cholinergic systems and their relation to the behavioral profile led Sara et al. (1994) to consider the Maudsley rat strains as a 'probe' to investigate noradrenergic-cholinergic interaction in learning and memory. The authors reported that, in comparison with the Reactive line, the Non reactive line was characterized by a greater $\left[{ }^{125} \mathrm{I}\right]$ clonidine binding to alpha 2 receptors in the locus coeruleus, a higher behavioral sensitivity to clonidine, and a greater availability of muscarinic receptors correlating with superior spatial working memory performance.

Similarly, the Naples High-Excitable and LowExcitable rat lines, bred for their different levels of activity reflecting behavioral arousal in a novel situation, show interesting behavioral and neural properties for investigating the role of the mesocortical dopaminergic system in cognitive and motor behavior In particular, the two lines differ in spatial learning, active avoidance, and conditioned taste aversion, with the HighExcitable line showing a performance very similar to that of rats injected with a dopaminergic agonist (Viggiano et al., 2002). In agreement with the behavioral data, regional examination of dopaminergic metabolism in these animals revealed a hyperdopaminergic innervation in the prefrontal cortex of the High-Excitable line, with a down regulation of dopamine D1 receptors making this line particularly suitable to the study of hyperactivity and attentional disorders (Carey et 
al., 1998), as well as drug abuse (Viggiano et al., 2003).

\section{Differential sensitivity to pharmacological treatment}

Indeed, pharmacologists interested in the functional role of a specific neurotransmitter system can directly use the responsiveness to a pharmacological agent for selecting lines showing extreme phenotypes. For example, Gallaher et al (1987) selected mice according to the effect of diazepam known for its anxyolitic, myorelaxing, and anticonvulsive properties in the rotarod test, which measures both muscular strength and motor coordination. Binding experiments, successively conducted on these subpopulations, showed linedependent differences in the number of benzodiazepine receptors that correlate with rotarod performance and seizure thresholds induced by convulsant agents. Interestingly, when lines of mice were also selected for their different sensitivity to diazepam but using a physiological (sleep time) instead of a behavioral (rotarod performance) criterion (Yoong \& Wong, 1988), the line with the lower reaction (and lower number of benzodiazepine receptors) also showed superior rotarod performance but, contrary to that observed in the Gallaher's experiments, no protection against pentylenetrazol-induced seizure. This set of findings underline that changing one element in a complex criterion of selection (drug responsiveness $\times$ behavioral $v s$ physiological trait) can lead to the segregation of very selective phenotypes.

This aspect is well illustrated by Chapouthier et al. (1998), who selected lines for their different sensitivity to the benzodiazepine receptor inverse agonist methyl- $\beta$-carboline-3-carboxylate ( $\beta$-CCM), known for its convulsant, anxiogenic, and learning enhancing effects. In these experiments, the criterion of selection was the latency to convulse following $\beta$-CMM administration. The two lines were easily separated: one line convulsing with short latencies and one line resistant to $\beta$-CMM administration. Binding analysis of benzodiazepine receptors in these two subpopulations indicated a decreased $\mathrm{B}_{\max }$ in the resistant line compared with the convulsing line. Interestingly, although selected for their responsiveness to a drug, these mice also showed a variety of line-specific, anxiety-related behavioral traits. In particular, the resistant line was found to display poor intermale aggression (Guillot et al., 1999), low anxiety levels (Suaudeau et al., 2000), and reduced sensitivity to other convulsive (GABA-A) agents (Rinaldi et al., 2000). The point to be examined now is whether a selection process based upon responsiveness to $\beta$-CCM, that is, a drug having learning-enhancing properties, also segregates for distinct learning abilities. Preliminary data indicate that segregation does occur, with the sensitive line showing the higher performance in spatial discrimination tasks (Venault et al., 2003)

\section{INBREEDING}

Inbreeding, also aimed at the production of distinct lines or strains, consists of mating closely related individuals (sisters and brothers) for many generations. In the mouse, for example, about 20 generations are necessary to produce an inbred line, the members of which are homozygous, i.e., have the same genotype. Worth remembering is that inbred mice were initially generated for physiopathologists, who early identified the advantage of having a homogeneous population of individuals showing a clear symptomatology. Therefore, the criteria of selection used by C.C. Little (1916) to produce inbred strains in the early $20^{\text {th }} \mathrm{c}$ entury were, for example, "immunohistocompatibility response" or "predisposition to develop neoplasia", to determine if cancer was inherited. Incidentally, Bagg (1920) tested various inbred strains of mice in several multiple-choice mazes and found that the learning performance strongly varied between 
strains whereas it was remarkably homogeneous within each strain. Later, Vicari (1929), who examined the time spent by $\mathrm{DBA} / 2 \mathrm{~J}$ and $\mathrm{BALBc} / \mathrm{J}$ inbred mice, as well as by "Japanese Waltzer" and "Myencephalic Blebs" mutant mice to run a threeunit maze, also observed that maze-running times were strain-dependent.

These observations led to an abundant body of literature dealing with inter-strain comparisons. Clearly, one advantage of inbreeding over bidirectional selection is that no learning-task-related criterion is involved in the selection process so that possible confounders relating to the effective performance-related criterion of selection are excluded. Another interesting aspect of inbreeding is that the individuals of a given strain are like homozygous twins, i.e., have identical genotypes. It turns out that an entire population exhibits the phenotype of a single randomly bred individual so that interstrain comparisons are overall a tool for analyzing interindividual phenotypic variability within natural populations. As many strains have been now accurately characterized (see Ingram \& Corfman, 1982, for an overview of neurobiological differences in mouse strains), any neuroscientist interested in analyzing a particular behavioral or neural phenotype can select $a$ priori either one strain expressing the behavioral or neural trait of interest, or several strains to be compared for their difference relating to this trait.

Strain differences in learning and memory performance: examples from $\mathrm{C} 57 \mathrm{BL} / 6$ vs $\mathrm{DBA} / 2$ comparisons

The initial observation of spontaneous differences in performance among inbred mice subjected to one learning task generated an impressive amount of experiments aimed at comparing strains in a variety of tasks taping different forms of memorization. The results showed no general learning superiority in any strain but did show frequent strain $\mathrm{x}$ task specific levels of performance. For example, C57BL/6 (C57) mice were found to perform worse than $\mathrm{DBA} / 2$ (DBA) mice in tasks having a strong procedural component, such as the Lashley maze (Oliverio et al., 1972) the active avoidance task (Bovet et al., 1969; Oliverio et al., 1972) or various situations of operant conditioning (Renzi \& Sansone, 1971). The C57 mice performed better in tasks requiring spatial (Ammassari et al., 1985; Crusio et al., 1980; Upchurch \& Wehner,1989; Passino et al., 2002) or contextual (Castellano \& Puglisi-Allegra, 1983; Weinberger et al., 1992; Restivo et al., 2002; Ammassari-Teule et al., 2000) information processing. A specific deficit in trace fear conditioning was reported in DBA mice (Holmes et al, 2002) otherwise showing superior performance in various protocols of conditioned taste aversion in comparison with C57 mice (Ingram 1982; Dudek \& Fuller, 1982; Risinger \& Cunningham, 1995) Conversely, both strains showed similar learning visual discrimination learning abilities (Castellano, 1977), as well as social transmission of social food preference (Holmes et al., 2002).

It is worth noting that such genetically associated differences in performance are not completely rigid because they can be either emphasized or attenuated through manipulating experimental factors. For example, when $\mathrm{C} 57$ and DBA mice are trained to press a lever to avoid an electric foot shock predicted by an auditory or a visual stimulus, DBA mice show superior avoidance performance when the duration of the predictive signal is short. Conversely, when the duration of the predicting signal is increased, interstrain differences in performance were no longer evident (Renzi \& Sansone, 1971).

Indeed, in view of the well-differentiated spatial learning abilities of C57 and DBA mice, an extensive description of the neural characteristics of the hippocampus was carried out in both strains 
to gain further insight on the relation between hippocampal functionality and spatial information processing. In agreement with the behavioral findings, C57 mice were found to show more mossy fiber terminals in the hippocampal regio inferior (Barber et al., 1974; Crusio et al., 1987; Schwegler et al., 1988), a higher hippocampal protein kinase C activity (Wehner et al., 1990), and a longer duration of the late phase of long term potentiation (Matsumaya et al., 1997; Nguyen et al., 2000; Jones et al., 2001) than DBA mice.

Fewer linear correlations emerged, however, when the cholinergic function, which plays a central role in spatial learning, was examined. That is, although interstrain differences regarding various aspects of cholinergic metabolism were clearly established, stating which strain was presenting the 'cholinergic properties' susceptible to mediate superior spatial learning and memory was impossible. For example, C57 mice showed a higher concentration and turnover of acetylcholine in the total brain, in the fronto-parietal cortex, and in the caudate nucleus than DBA mice (Durkin et al., 1973; Racagni et al., 1977). The synthesis of acetylcholine, estimated by measuring the activity of the enzyme choline acetyltransferase, was, however, more important in DBA than in C57 mice (Ebel et al., 1973; Mandel et al, 1974). Conversely, the degradation of acetylcholine, estimated by measuring the enzyme acetylcholinesterase, was found to be more intense in C57 than in DBA (Pryor et al., 1966), even if a higher content of acetylcholinesterase in the striatum of DBA was also found (Iacopino et al., 1985). Examination of the density of muscarinic receptors by autoradiographic methods, using $\left[{ }^{3} \mathrm{H}\right]$ quinuclidinyl benzilate $(\mathrm{QNB})$ and $\left[{ }^{3} \mathrm{H}\right]$ pirenzepine as ligands revealed lower $\left[{ }^{3} \mathrm{H}\right] \mathrm{QNB}$ binding in the frontal cortex, in the hippocampus, and in the striatum of $\mathrm{C} 57$ as compared with DBA, whereas $\left[{ }^{3} \mathrm{H}\right]$ pirenzepine binding in the temporal cortex was found to be higher in C57 (Marks et al.,
1981; Schwab et al., 1990) than in DBA. These observations underline the difficulty of establishing fully consistent causal relations when various levels of analysis are taken into account. Nevertheless, the well-differentiated reactivity of inbred strains to pharmacological agents has proved to be useful for unveiling how various modalities of interaction between neurotransmitters systems exert a specific control on behavior.

\section{Inbred mice: variable responsiveness to drugs in learning and memory tasks}

Experiments widely based on the post-training administration of drugs in the passive avoidance task have shown that inbred mice show a variable responsiveness to drugs, with differences in the intensity as well as in the direction of the effects. A few examples still relating to C57 and DBA strain comparisons illustrate this phenomenon. For instance, the cholinergic muscarinic agonist oxotremorine improves passive avoidance retention in both strains, with a stronger effect in DBA, whereas the serotonergic agonist 5-MeODMT impairs retention to the same extent in each genotype. The simultaneous administration of 5MeODMT and oxotremorine, however, specifically blocks the improving effect of the cholinergic agonist on memory consolidation only in the DBA strain (Pavone et al., 1993).

In the same fashion, also the interplay between cholinergic and dopaminergic mechanisms in mediating memory consolidation differs according to genotype. That is, the D2 dopaminergic agonist quinpirole and the D2 antagonist (-) sulpiride were reported to impair retention in $\mathrm{C} 57$ and to produce inverted effects in DBA. Nevertheless, the strainrelated facilitating or impairing effects of quinpirole and sulpiride are blocked by the simultaneous administration of oxotremorine (Gasbarri et al. 1997; Castellano et al., 1999). Both series of experiments demonstrated, therefore, that 
in each genotype, the serotonergic as well as the dopaminergic modulation of memory processes are mediated via muscarinic receptors. Consistent with these observations is the finding that the effect of dopamine agonists on hippocampal acetylcholine release in vivo is also strain-dependent (Imperato et al., 1996). Indeed, genotype-specific effects of single drugs mediated by complex interactions between distinct neurotransmitters systems were also reported for cholinergic muscarinic (AmmassariTeule \& Caprioli, 1985; Marks et al., 1981) or for nicotinic agents (Gilliam \& Schlesinger, 1985; Marks et al., 1986), glutamate NMDA-competitive and NMDA-noncompetitive antagonists (Ungerer et al., 1993, Cestari et al, 1999; Ciamei et al., 2000), opioids agonists (Castellano, 1980; Puglisi-Allegra et al., 1994; Castellano \& Pavone, 1987; Castellano et al., 1996; Ciamei et al., 2000), GABA (Castellano et al., 1993), endogenous cannabinoids (Castellano et al., 1999), and adenosine (Castellano, 1977a), as well as antipsychotic and antidepressant agents broadly interacting with the catecholamines (Castellano, 1977b).

Interesting properties of cognitive enhancers have also been unveiled by comparing their effect in different inbred strains of mice. For example, the nootropic drug oxiracetam was found to produce stronger enhancing effects on avoidance acquisition in the good-performer strain (BALB/cJ) than in the poor-performer strain (C57), whereas the nootropic drug piracetam facilitated acquisition only in the good-performer strain BALB/cJ. These observations led to the conclusion that nootropics have a marginal influence on individuals spontaneously showing low levels of performance (Sansone et al., 1985). Importantly, the combination of oxiracetam and methamphetamine boosted the active avoidance performance of poor-performer strain C57 mice up to the level of the good-performer strain BALBc/J (Sansone \& Oliverio, 1989), with the enhancing effect of the drug combination being superior to the effect of oxiracetam or methamphetamine alone.

\section{CONCLUSIONS}

Although non-exhaustive, this short review allows certain conclusions to be drawn about the interest and the limits of a genetic dissection based upon Mendelian principles in the field of the pharmacology of memory.

Certainly, what both bidirectional and inbreeding experiments show is that segregating lines or strains for one complex behavioral trait implies the selection of a variety of superimposed traits. Independently of the precise genetic mechanism underlying the multiple-segregation phenomenon (linkage, polygenic systems), there is no doubt that a stable set of associated traits provided a unique opportunity to identify causal relations between phenomena at different levels of integration.

Another advantage deriving from the selection of extreme phenotypes is the possibility of estimating the amplitude of normal inter-individual variations for a particular trait. In fact, as bidirectional selection and inbreeding techniques are applied on normal populations, the point to be remembered is that 'low' learners are still 'normal' learners, and that the sometimes opposite effects of one drug on strain-specific levels of performance are within the normal range of this drug's effects. Nevertheless, that the neurochemical characteristics of low learners can be considered as 'prepathological' and can serve to identify early markers of cognitive dysfunction is also true. For example, the properties of the noradrenergic system of non-reactive Maudsley rats (Slater et al., 1977; Buda et al., 1994), of the dopaminergic system of High Excitable Naples rats (Carey et al., 1998), or of the glutamatergic system of DBA mice (Ungerer et al., 1993), although in a normal range, are highly predictive of learning and memory dysfunction.

Finally, beyond the mere observation of strainspecific differences in performance, quantitative 
genetics methods have also used inbreeding to identify single gene or polygenic systems controlling specific behavioral or biological traits. These methods are largely based upon crossing techniques aimed at segregating various gene combinations. Among those are the classical Mendelian analysis (cross of two parental strains giving a $\mathrm{F} 1$ generation, subsequent cross of $\mathrm{F} 1$ individuals to obtain a F2 generation, and backcross of $\mathrm{F} 2$ individuals with the parental strains), the diallelic crossing (set of possible combinations between six or eight homozygous strains), the production of congenic lines (cross of two parental strains and subsequent backcross of F1 individuals with one parental strain) or of recombinant lines (cross of two homozygous parental strains giving a $\mathrm{F} 1$ generation maintained under a strict inbreeding regimen). This approach, however, has shown that single gene-dependent behaviors are rare (Oliverio et al., 1973). Conversely, many single genes were found to influence multiple behavioral and physiological traits, which were in turn controlled by multiple genes acting at various levels: enzymatic activity, hormones, neurochemistry, neurophysiology, neuromorphology, neural differentiation. For instance, phenylketonuric patients have a metabolic defect controlled by a single mutated autosomal recessive gene that influences a variety of genes, thereby promoting a complete biochemical and mental syndrome.

Additionally, the calculation of heritability-a biometric method considering the ratio between the observed and the expected variance of a behavioral trait-has been widely used by behavioral geneticists, although it sometimes provided unreliable results. For example, in a cross between the alcohol-preferring C57 and the alcohol-avoiding A strain, the F1 and F2 means of heritability were found to be intermediate between the parents, and backcrosses to the parental strains were also in the expected directions. The variance of the F3 generation, however, was smaller than that of the F1, making the computation of heritability meaningless (Rodgers \& McClearn, 1962)

Thus, although bidirectional and inbreeding still provide excellent tools for dissecting the neurochemical bases of memory through the segregation of well-differentiated phenotypes, the interest for the quantitative genetics approach is progressively decreasing in favor of molecular genetics. There is no doubt that gene sequencing and microarray techniques can provide a more direct picture on what is really happening at the chromosomal level. Nevertheless, the lessons learned from Mendelian genetics should be retained by molecular geneticists. Among those are - controlling gene dominance, recession, heterosis, and recombination when various transgenic mice are crossed to produce double or triple transgenic individuals, and

- keeping in mind that if inbred strains show single-individual phenotypes, transgenic or knockout mice derived from such strains will provide marginally-relevant information for the majority of random bred individuals.

\section{REFERENCES}

Ammassari-Teule M, Caprioli A. 1985. Spatial learning and memory, maze running strategies and cholinergic mechanisms in two inbred strains of mice. Behav Brain Res 17: 9-16.

Ammassari-Teule M, Passino E, Restivo L, and de Marsanich B. 2000. Fear conditioning in C57/BL/6 and DBA/2 mice: variability in nucleus accumbens function according to the strain predisposition to show contextual- or cue-based responding. Eur J Neurosci 12: 4467-4474.

Bagg HJ. 1920. Individual differences and family resemblances in animal behavior. In: Woodworth RS, ed, Archives of Psychology, No. 43. New York, NY, USA: The Science Press.

Barber RP, Vaughn J., Wimer RE, Wimer CC. 1974. Genetically associated variations in the distribution of dentate granule cell synapses upon the pyramidal cell dendrites in mouse hippocampus. $\mathrm{J}$ 
Comp Neurol 156: 417-434.

Bignami G. 1965. Selection for high rates and low rates of conditioning in the rat. Anim Behav 13: 221-227.

Bignami, G, Robustelli, F, Janku, J, Bovet, D. 1965. Action of amphetamine and some psychotropic agents on the acquisition of an escape and avoidance conditioning in rats selected as a function of the especially low level of their performances. C R Acad Sci Hebd Seances Acad Sci D 260: 4273-4278.

Bovet D, Bovet-Nitti F, Oliverio A. 1969. Genetic aspects of learning and memory in mice. Science 163: 139-149.

Broadhurst PL. 1960. Applications of biometrical genetics to the inheritance of behaviour. In: Eysenck HJ, ed, Experiments in Personality, vol 1. Psychogenetics and Psychopharmacology. London, UK: Routledge Kegan Paul; 1-102.

Broadhurst PL. 1964. The hereditary base for the action of drugs on animal behaviour. In: Steinberg H, De Reuck AVS, eds, Animal Behaviour and Drug Action. Ciba Foundation Symposium jointly with the Co-ordinating Committee for Symposia on Drug Action. London, UK: J. \& A. Churchill, Ltd.; 224-237.

Brush FR. 2003a. Selection for differences in avoidance learning: the Syracuse strains differ in anxiety, not learning ability. Behav Genet 33: 677-696.

Brush FR. 2003b. The Syracuse strains, selectively bred for differences in active avoidance learning, may be models of genetic differences in trait and state anxiety. Stress 6: 77-85.

Brush FR, Froehlich JC, Sakellaris PC. 1979. Genetic selection for avoidance behavior in the rat. Behav Genet 9: 309-316.

Buda M, Lachuer J, Devauges V., Barbagli B, Blizard D, Sara SJ. 1994. Central noradrenergic reactivity to stress in Maudsley rat strains. Neurosci Lett 167: 33-36.

Carey MP, Diewald LM, Esposito FJ, Pellicano MP, Gironi Carnevale UA., Seargeant JA, et al. 1998. Differential distribution, affinity, plasticity and dopamine D-1 and D-2 receptors in the target sites of the mesolimbic system in an animal model of ADHD. Behav Brain Res 94: 173-185.

Castellano C. 1977a. Effects of pre- and post-trial caffeine administrations on simultaneous visual discrimination in three inbred strains of mice. Psychopharmacology (Berl) 51: 255-258.
Castellano C. 1977b. Effects of chlorpromazine and imipramine on discrimination learning, consolidation, and learned behavior in two inbred strains of mice. Psychopharmacology (Berl) 53: 27-31.

Castellano C. 1980. Dose dependent effects of heroin on memory in two inbred strains of mice. Psychopharmacology 67: 235-239.

Castellano C, Pavone F. 1987. Effects of the selective kappa-opioid receptor agonist U-50,488 on locomotor activity and passive avoidance behaviour in DBA/2 and C57BL/6 mice. Arch Int Pharmacodyn Ther 288: 270-280.

Castellano C, Puglisi-Allegra S. 1983. Strain-dependent modulation of memory by stress in mice. Behav Neural Biol 38: 133-138.

Castellano C, Cestari V, Cabib S, Puglisi-Allegra S. 1993. Strain-dependent effects of post-training GABA receptor agonists and antagonists on memory storage in mice Psychopharmacology (Berl) 111: 134-138.

Castellano C, Zocchi A, Cabib S, Puglisi-Allegra S. 1996. Strain-dependent effects of cocaine on memory storage: improvement induced by posttraining physostigmine. Psychopharmacology (Berl) 123: 340-345.

Castellano C, Ventura R, Cabib S, Puglisi-Allegra S. 1999a. Strain-dependent effects of anandamide on memory consolidation in mice are antagonized by naltrexone. Behav Pharmacol 1999. 10: 453-457

Castellano C, Cabib S, Puglisi-Allegra S, Gasbarri A, Sulli A, Pacitti C, et al. 1999b. Strain-dependent involvement of D1 and D2 dopamine receptors in muscarinic cholinergic influences on memory storage. Behav Brain Res 98: 17-26.

Cestari V, Ciamei A, Castellano C. 1999. Straindependent effects of MK-801 on passive avoidance behaviour in mice: interactions with morphine and immobilization stress. Psychopharmacology 146: 144-152.

Chapouthier G, Launay, JM, Venault P, Breton C, Roubertoux P, Crusio WE. 1998. Genetic selection of mouse lines differing in sensitivity to a benzodiazepine receptor inverse agonist. Brain Res 787: 85-90.

Ciamei A, Cestari V, Castellano C. 2000. Straindependent interactions between $\mathrm{MK}-801$ and cocaine on retention of $\mathrm{C} 57 \mathrm{BL} / 6$ and $\mathrm{DBA} / 2$ mice tested in a one-trial inhibitory avoidance task: involvement of dopaminergic mechanisms. Neurobiol Learn Mem 73: 188-194. 
Dudek BC, FullerJH. 1978. Task-dependent genetic influences on behavioral response of mice (Mus musculus) to acetaldehyde. J Comp Physiol Psychol 92: 749-758.

Durkin T, Ayad G, Ebel A, Mandel P. 1973. Comparative study of acetylcholine turnover rates in the brains of three inbred strains of mice: correaltion with some interstrain differences. Brain Res 136: 475-486

Ebel A, Hermatet JC, Mandel P. 1973. Comparative study of acetylcholinesterase and choline acetyltransferase enzyme activity in brain of DBA and C57 mice. Nat New Biol 242: 56-58.

Gallaher EJ, Hollister LE, Gionet SE, Crabbe JC. 1987. Mouse lines selected for genetic differences in diazepam sensitivity. Psychopharmacology 93: 25-30.

Gasbarri A, Sulli A, Pacitti C, Puglisi-Allegra S, Cabib S, Castellano C, et al. 1997. Strain-dependent effects of D2 dopaminergic and muscariniccholinergic agonists and antagonists on memory consolidation processes in mice. Behav Brain Res 86: 97-104.

Gilliam DM, Schlesinger K. 1985. Nicotine-produced relearning deficit in $\mathrm{C} 57 \mathrm{BL} / 6 \mathrm{~J}$ and $\mathrm{DBA} / 2 \mathrm{~J}$ mice. Psychopharmacology (Berl) 86: 291-295.

Giorgi, O, Orlandi M, Escorihuela RM, Driscoll P, Lecca D, Corda MG. 1994. GABAergic and dopaminergic transmission in the brain of Roman high-avoidance and Roman low-avoidance rats. Brain Res 638: 133-138.

Guillot PV, Sluyter F, Crusio WE, Chapouthier G. 1999. Mice selected for differences in sensitivity to a benzodiazepine receptor inverse agonist vary in intermale aggression. Neurogenetics 2: 171175.

Heron WT. 1935. The inheritance of maze learning ability in rats. J Comp Psychol 19: 77-89:

Holmes A, Wrenn CC, Harris AP, Thayer KE, Crawley JN. 2002. Behavioral profiles of inbred strains on novel olfactory, spatial and emotional tests for reference memory in mice. Genes Brain Behav 1: 55-69.

Iacopino C, Altavista MC, Gozzo S, Albanese A. 1986. Quantitative pharmacohistochemistry of acetylcholinesterase in neostriatum of inbred strains of mice. Brain Res 374: 402-408.

Imperato A, Obinu MC, Mascia MS, Casu MA, Zocchi A, Cabib S, et al. 1996. Strain-dependent effects of dopamine agonists on acetylcholine release in the hippocampus: an in vivo study in mice. Neuroscience 70: 653-660.

Ingram DK, Corfman TP. 1980. An overview of neurobiological comparisons in mouse strains. Neurosci Biobehav Rev 4: 421-435.

Ingram DK. 1982. Lithium chloride-induced taste aversion in $\mathrm{C} 57 \mathrm{BL} / 6 \mathrm{~J}$ and $\mathrm{DBA} / 2 \mathrm{~J}$ mice. $\mathrm{J}$ Gen Psychol 106: 233-249.

Jones MW, Peckham HM, Errington ML, Bliss TV, Routtenberg A. 2001. Synaptic plasticity in the hippocampus of awake $\mathrm{C} 57 \mathrm{BL} / 6$ and $\mathrm{DBA} / 2$ mice: interstrain differences and parallels with behavior. Hippocampus 11: 391-396.

Lazega D, Driscoll P, Frischknecht HR, Siegfreid B, Waser PG. 1986. Opiate receptor binding and behavioral effects of morphine in RHA/Verh and RLA/Verh rats. NIDA Res Monogr 75: 485-488.

Liang B, Blizard DA. 1978. Central and peripheral norepinephrine concentrations in rat strains selectively bred for differences in response to stress: confirmation and extension.. Pharmacol Biochem Behav 8: 75-80.

Lipp HP, Schwegler H, Heimrich B, Cerbone A, Sadile AG. 1987. Strain-specific correlations between hippocampal structural traits and habituation in a spatial novelty situation. Behav Brain Res 1987. 24: 111-123.

Little CC, Tyzzer EE. 1916. A Mendelian explanation of rejection and susceptibility. J Med Res 33: 393-425.

Mandel P, Ayad G, Hermetet JC, Ebel A. 1974. Correlation between choline acetyltransferase activity and learning ability in different mice strains and their offspring. Brain Res 72: 65-70.

Marks MJ, Patinkin DM, Artman LD, Burch JB, Collins AC. 1981. Genetic influences on cholinergic drug response. Pharmacol Biochem Behav 15: 271279.

Matsuyama S, Namgung U, Routtenberg A. 1997. Long-term potentiation persistence greater in C57BL/6 than DBA/2 mice: predicted on basis of protein kinase $\mathrm{C}$ levels and learning performance. Brain Res 763: 127-130.

Nguyen PV, Abel T, Kandel ER, Bourtchouladze R. 2000. Strain-dependent differences in LTP and hippocampus-dependent memory in inbred mice. Learn Mem 7: 170-179.

Oliverio A, Castellano C, Messeri P. 1972. Genetic analysis of avoidance, maze, and wheel-running behaviors in the mouse. J Comp Physiol Psychol 
79: $459-473$.

Oliverio A, Eleftheriou BE, Bailey DW. 1973. Exploratory activity: genetic analysis of its modification by scopolamine and amphetamine. Physiol Behav 10: 893-899.

Passino E, Middei S, Restivo L, Bertaina-Anglade V, Ammassari-Teule M. 2002. Genetic approach to variability of memory systems: analysis of place vs. response learning and fos-related expression in hippocampal and striatal areas of C57BL/6 and DBA/2 mice. Hippocampus 12: 63-75.

Pavone F, Fagioli S, Castellano C. 1993. Effects of oxotremorine on inhibitory avoidance behaviour in two inbred strains of mice: interaction with 5methoxy-NN-dimethyltriptamine. Psychopharmacology (Berl) 112: 249-252.

Pryor GT, Schlesinger K, Calhoun WH. 1966. Differences in brain enzymes among five inbred strains of mice. Life Sci 5: 2105-2111.

Puglisi-Allegra S, Cestari V, Cabib S, Castellano C. 1994. Strain-dependent effects of post-training cocaine or nomifensine on memory storage involve both D1 and D2 dopamine receptors. Psychopharmacology (Berl) 115: 157-162.

Renzi P, Sansone M. 1971. Discriminated lever-press avoidance behavior in mice. Commun Behav Biol 6: 315-321.

Restivo L, Passino E, Middei S, Ammassari-Teule M. 2002. The strain-specific involvement of nucleus accumbens in latent inhibition might depend on differences in processing configural- and cuebased information between C57BL/6 and DBA mice. Brain Res Bull 57: 35-39.

Rinaldi D, Boutrel B, Adrien J, Venault P, Chapouthier G, Boutre B. 2000. Two mouse lines selected for differential sensitivities to betacarboline-induced seizures are also differentially sensitive to various pharmacological effects of other GABA(A) receptor ligands. Behav Genet 30: 277-284.

Risinger FO, Cunningham CL. 2000. DBA/2J mice develop stronger lithium chloride-induced conditioned taste and place aversions than C57BL/6J mice. Pharmacol Biochem Behav 67: 17-24.

Rodgers DA, McLean GE. 1962. Alcohol preference of mice. In: Bliss EL, ed, Roots of Behavior. New York, New York, NY, USA: Harper; 68-95.

Sansone M, Oliverio A. 1989. Avoidance facilitation by nootropics. Prog Neuropsychopharmacol Biol
Psychiatry 13 Suppl: S89-S97.

Sansone M, Castellano C, Ammassari-Teule M. 1985. Improvement of avoidance acquisition by the nootropic drug oxiracetam in mice. Arch Int Pharmacodyn Ther 275: 86-92.

Sara SJ, Devauges V, Biegon A. 1993. Maudsley rat strains, selected for differences in emotional responses, differ in behavioral response to clonidine and in [125I]clonidine binding in the locus coeruleus. Behav Brain Res 57: 101-104.

Sara SJ, Devauges V, Biegon A, Blizard DA. 1994. The Maudsley rat strains as a probe to investigate noradrenergic-cholinergic interaction in cognitive function. J Physiol Paris 88: 337-345.

Satinder KP. 1980. Interaction among scopolamine, conditioned stimulus modality, genotype, and either-way avoidance behavior of rats. Psychopharmacology (Berl) 67: 97-99.

Schwab C, Bruckner G, Castellano C, Oliverio A, Biesold D. 1990. Different levels of acetylcholinesterase and choline acetyltransferase activities in $\mathrm{C} 57 \mathrm{Bl} / 6$ and $\mathrm{DBA} / 2$ mice are not accompanied with different density of cortical acetylcholinesterase reactive fibers. Neurochem Res 15: 1127-1133.

Schwegler H, Crusio WE, Lipp HP, Heimrich B. 1988. Water-maze learning in the mouse correlates with variation in hippocampal morphology. Behav Genet 18: 153-165.

Slater J, Blizard DA, Pohorecky LA. 1977. Central and peripheral norepinephrine metabolism in rat strains selectively bred for differences in response to stress. Pharmacol Biochem Behav 6: 511-520.

Suaudeau C, Rinaldi D, Lepicard E, Venault P, Crusio WE, Costentin J, Chapouthier G. 2000. Divergent levels of anxiety in mice selected for differences in sensitivity to a convulsant agent. Physiol Behav 71: 517-523.

Thompson WR. 1954. The inheritance and development of intelligence. Res Publ Assoc Res Nerv Ment Dis 33: 209-231.

Tryon RC. 1940. Genetic differences in mazelearning ability in rats. Natl Soc Study Educ Yearbook 39: 111-119.

Ungerer A, Melan C, De Barry J. 1993. Straindependent effects of gamma-L-glutamyl-L-aspartate, a NMDA antagonist, on retention of a Y-maze avoidance learning task in mice. Behav Brain Res 55: 69-75.

Upchurch M, Wehner J. 1989. Inheritance of spatial 
learning ability in inbred mice: a classical genetic analysis. Behav Neurosci 103: 1251-1258.

Venault P, Béracochea $D$, Valleau $M$, Joubert C, Chapouthier G. 2003. Mice selected for differences in sensitivity to a benzodiazepine receptor inverse agonist also differ in learning abilities. Bruges, Belgium: World Federation of Societies of Biological Psychiatry Symposium (Abstract).

Vicari EM. 1929. Modes of inheritance of reaction time and degrees of learning in mice. J Exp Zool 54: 31-88.

Viggiano D, Ruocco LA, Pignatelli M, Grammatikopoulos G, Sadile AG. 2003. Prenatal elevation of endocannabinoids corrects the unbalance between dopamine systems and reduces activity in the Naples High Excitability rats. Neurosci Biobehav
Rev 27:129-139.

Viggiano D, Vallone D, Welzl H, Sadile AG. 2002. The Naples High- and Low-Excitability rats: selective breeding, behavioral profile, morphometry, and molecular biology of the mesocortical dopamine system. Behav Genet 32: 315-333.

Wehner JM, Sleight S, Upchurch M. 1990. Hippocampal protein kinase $C$ activity is reduced in poor spatial learners. Brain Res 523: 181-187.

Weinberger SB, Koob GF, Martinez JL. 1992. Differences in one-way active avoidance learning in mice from three inbred strains. Behav Genet 22: 381-391.

Yoong YL, Wong PT. 1988. Selective breeding of mice for differential sensitivity to diazepam. Behav Genet 18: 185-191. 

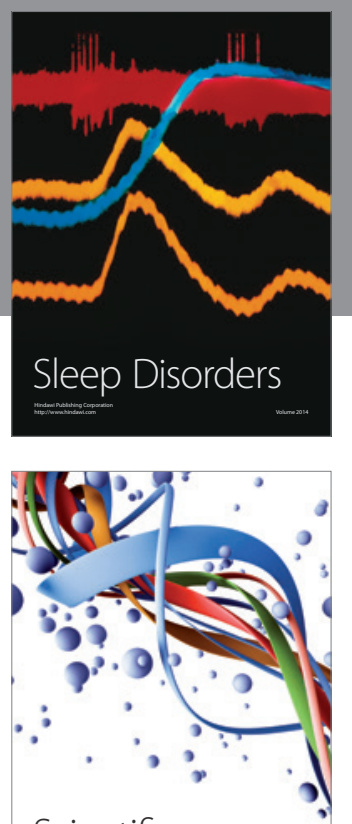

Scientifica
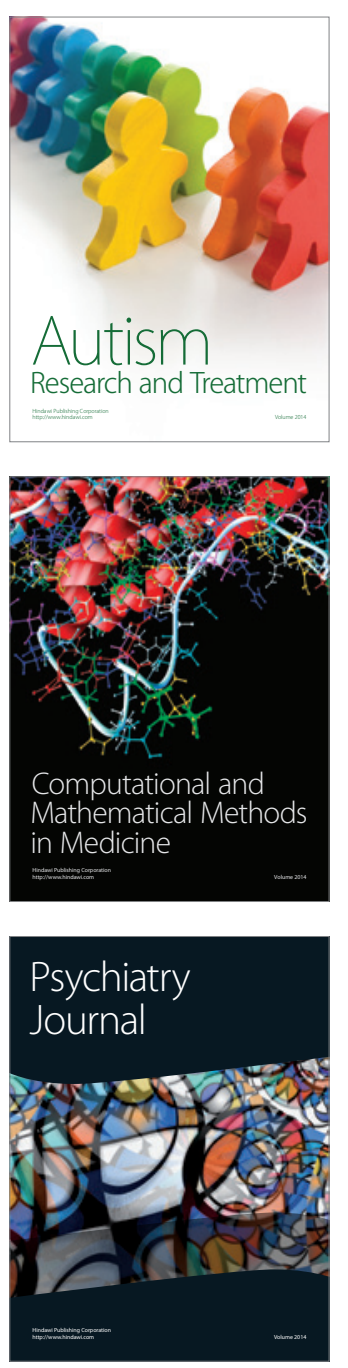
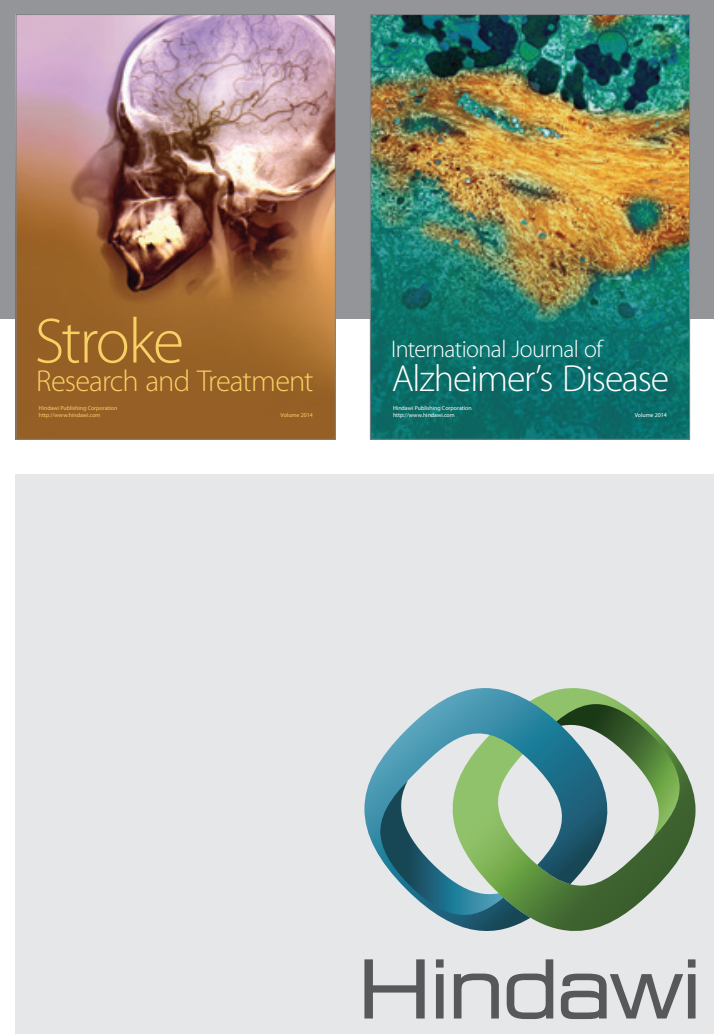

Submit your manuscripts at

http://www.hindawi.com
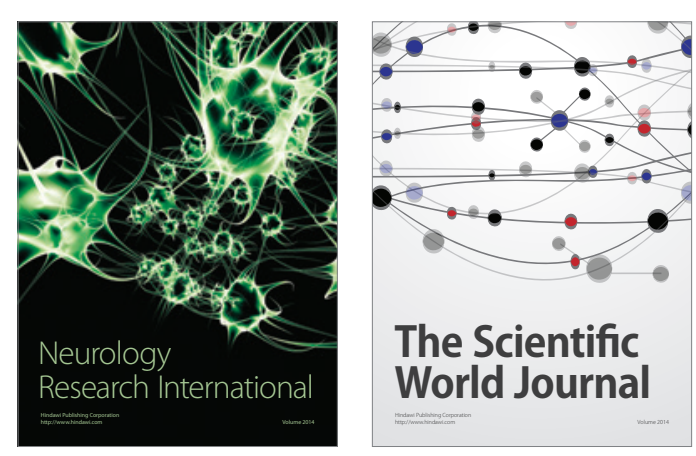

The Scientific World Journal

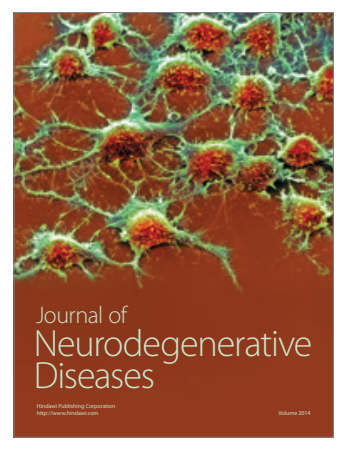

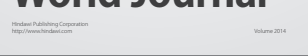

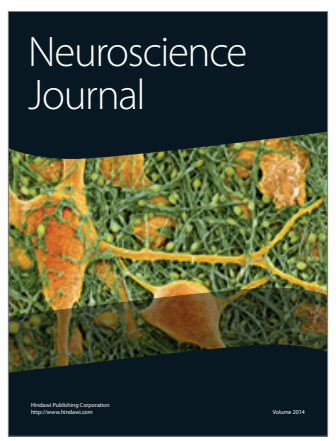

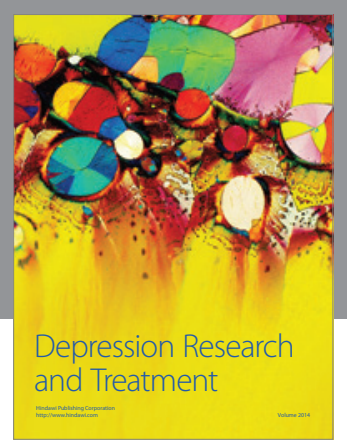
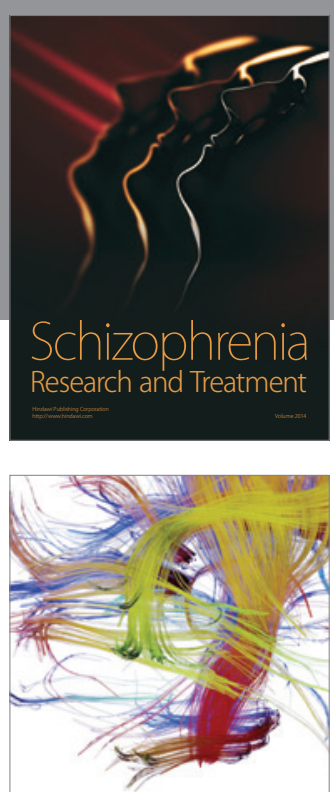

Brain Science

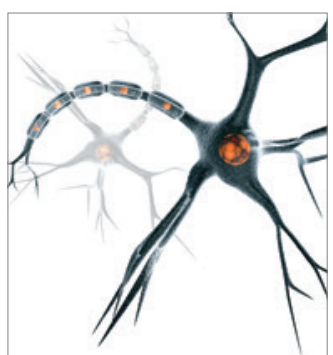

Neural Plasticity
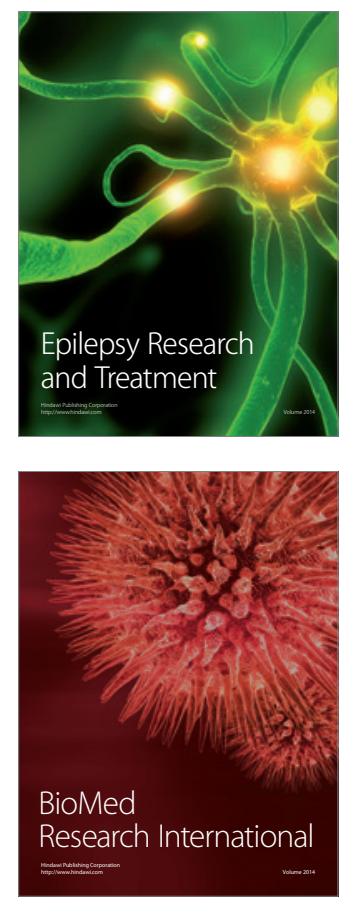

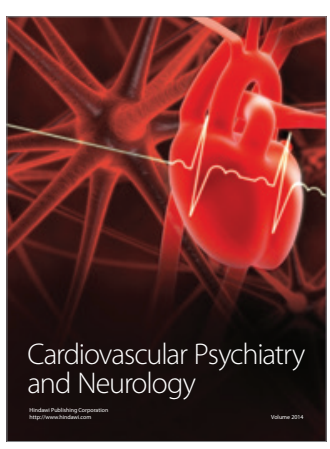

Parkinson's

Disease
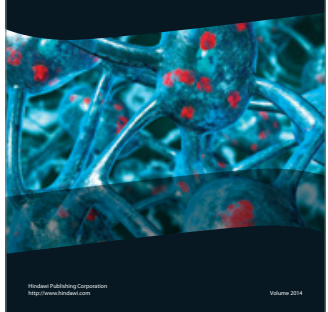